\title{
Cardiac Valve Regurgitant Jet Direction
}

National Cancer Institute

\section{Source}

National Cancer Institute. Cardiac Valve Regurgitant Jet Direction. NCI Thesaurus. Code C127563.

The anatomic trajectory of the retrog rade blood flow from a cardiac valve. 